\title{
Induced Mutants in Locally Adapted Landraces of French Bean (Phaseolus vulgaris L.), their Mutagenic Sensitivity and Mutability for Crop Improvement
}

\section{Sanjeev Kumar ${ }^{1 *}$, Mohar Singh ${ }^{2}$, Nikhil Malhotra ${ }^{2}$, Archna Joshi Saha ${ }^{3}$, Sanjay Jambhulkar ${ }^{3}$, JP Sharma ${ }^{4}$ and Manmohan Singh ${ }^{1}$}

${ }^{1}$ Pulses Research Sub-Station Samba, SKUAST-Jammu, India

${ }^{2}$ ICAR-National Bureau of Plant Genetic Resources Regional Station Shimla, India

${ }^{3}$ Nuclear Agriculture and Biotechnology Division, BARC Mumbai, Maharashtra,

India

${ }^{4}$ Directorate of Research, SKUAST-Jammu, India

*Corresponding Author: Sanjeev Kumar, Pulses Research Sub-Station Samba, SKUAST-Jammu, India.
Received: August 21, 2021

Published: November 20, 2021

(C) All rights are reserved by Sanjeev Kumar., et al.

\begin{abstract}
Mutagenesis is an important breeding strategy to enhance mutation frequency which enables studies of functional genomics and development of new genotypes. An attempt was made to induce mutagenesis into named landraces of french bean viz. Bhaderwah Local (BL) and Poonch Local (PL) with gamma rays and ethyl methane sulphonate (EMS) to determine their sensitivity and mutability. Landrace PL was more sensitive than BL to both the mutagens. The $\mathrm{LD}_{50}$ of germination percentage for BL and PL was determined as 248.058 Gy and 234.167 Gy, respectively. The maximum number of chlorophyll mutants was found in BL than PL to both mutagens. Gamma rays doses were found to be more effective in both the landraces for the generation of chlorophyll mutants. Mutants in $\mathrm{M}_{2}$ generation of BL screened under $200 \mathrm{~Gy}$ and $250 \mathrm{~Gy}$ showed high resistance against anthracnose and moderate resistance of EMS induced mutants under 150 Gy and 225 Gy doses. These genetic stocks could be useful for allele mining and creation of variability for widening the genetic base of traditional landraces of french bean.
\end{abstract}

Keywords: Phaseolus vulgaris; $\mathrm{LD}_{50}$; Chlorophyll Mutations; Mutagen Sensitivity; Radio Sensitivity; Crop Improvement

\section{Introduction}

Genetic diversity is required for any crop improvement programme, and when it is lacking in the gene pool, hybridization and mutations are the only tools available to increase allelic variations [3]. It is well known that extreme diversity exists between biological organisms in their response to mutagens. The response to seed treatment with various mutagens provides valuable information for mutation breeding because it simplifies the planning of experiments aimed at increasing mutation frequency. Further, crop genetic improvement is dependent on the amount of genetic variability in the population. However, the available genetic variability within the cultivated gene pool has been exploited to the maximum level of productivity in french bean (Phaseolus vulgaris L.), necessitating the creation of additional variations through mu- tations. In general, mutation breeding has contributed significantly to the improvement of self-pollinated crops such as cowpea [8], black gram [27], soybean [18,19] etc. Although there are several techniques used for mutation breeding, gamma ray is one of the most promising physical mutagens which have been used for inducing biotic and abiotic stress tolerance in seed propagating crops $[21,10]$. To date, various new crop cultivars have been developed in anthurium [20], coriander [22], mungbean [23] and tomatoes [25], using gamma rays treatments. Furthermore, the ionizing radiation method has also played an important role in the development of superior plants with economically important traits [10]. Also, chlorophyll mutations may be useful in understanding the various physiological functions, biochemical reactions, and pathological invasion when determining the effectiveness of mutagens. 
Although mutagens cause changes in nucleotide sequence of DNA and the mode of action of each mutagen is unique, the accompanying undesirable effects like lethality or sterility may decrease its efficiency. Thus, in order to exploit induced mutagenesis for crop improvement, mutagens must be effective and efficient in order to produce the desired effects [2,17]. Therefore, the present study has been aimed at understanding the mutagen sensitivity of local named landraces of french bean belonging to Jammu and Kashmir province of India, including similarities or differences between landraces with regard to radio and chemo sensitivity, mutability, relationship between mutagen sensitivity and mutability using gamma-rays and ethyl methane sulphonate (EMS).

\section{Materials and Methods}

Genetic materials

The genetic materials used in the present study were two named landraces of french bean, Bhaderwah Local (BL) and Poonch Local (PL). The orthodox seed samples of these two landraces were exposed to 50,100,150, 200 and 250 Gy gamma rays using 5500 Ci 60Co Gamma-chamber 4000 at Bhabha Atomic Research Centre (BARC) in India with dose rate of 120 . The same genetic materials were also treated with 0.00 (control), 0.1, 0.2, 0.3, 0.4, 0.5, 0.6, $0.7,0.8,0.9$ and $1.0 \%$ solution of ethyl methane sulphonate (EMS) that were prepared in phosphate buffer solution at $\mathrm{pH} 7.0$ for $6 \mathrm{hrs}$ with intermittent shaking at $25^{\circ} \mathrm{C}$. After the chemical treatment, the seeds were gently washed under running tap water for half an hour. The seed material treated with mutagens along with 100 untreated control seeds (soaked in phosphate buffer only) were sown immediately in the germinating trays and field without any posttreatment. The observations such as root length, shoot length and number of leaves of 7 - days old seedlings grown at $25 \pm 1^{\circ} \mathrm{C}$ temperature and $97 \%$ relative humidity under laboratory conditions were used to assess the dose response. The $\mathrm{LD}_{50}$ was calculated for root length, shoot length, number of leaves and germination percentage. Then, $\mathrm{LD}_{50}$ with respect to biological parameters was determined using the regression equation of $\mathrm{Y}$ (dose) on $\mathrm{X}$ (damage) as $\mathrm{Y}=\mathrm{a}+\mathrm{bx}$. The seeds from each $\mathrm{M}_{1}$ plant were harvested separately. Further, $M_{1}$ plant progenies were grown in order to score the chlorophyll mutations in $\mathrm{M}_{2}$ generation. The frequency of chlorophyll mutations was calculated as percentage of families segregating for any type of chlorophyll mutation ( $\mathrm{M}_{2}$ family basis) as well as percentage of chlorophyll mutants in the population of a particular treatment $\left(\mathrm{M}_{2}\right.$ mutant basis). The mutation frequency is one of the most dependable indices for evaluating the genetic effects of mutagenic treatments [11]. It was calculated as percentage of mutated $\mathrm{M}_{2}$ progenies for both chlorophyll as well as morphological mutations of each treatment. The genetic materials were grown in bulk populations and the mutant frequency was estimated by dividing the total number of mutants confirmed by the total number of $\mathrm{M}_{2}$ plants in the bulk population [7].

\section{Results}

The present study revealed that germination percentage, root and shoot length along with number of leaves decreased progressively with increasing doses of gamma rays and EMS in both BL and PL landraces. The study indicated significant correlation coefficients of biological parameters with the doses of mutagens (Figure $1 \mathrm{a}, 1 \mathrm{~b}$ and $2 \mathrm{a}, 2 \mathrm{~b}$ ). The dose dependent relationship was observed for different biological parameters in $M_{1}$ generation of two landraces with both physical mutagen (gamma rays) and chemical mutagen (ethyl methane sulphonate). Overall, the biological parameter doses and traits in percentage were inversely proportional to each other. However, reduction in $50 \%$ germination percentage occurred at 248.058 Gy gamma rays in BL and 234.167 Gy in PL along with $0.626 \%$ in BL and $0.573 \%$ in PL with ethyl methane sulphonate (Table 1). The reduction in number of leaves to an extent of $50 \%$ was caused by 9.573 Gy in BL and 7.278 Gy in PL with $0.005 \%$ and $0.004 \%$, respectively. $\mathrm{LD}_{50}$ for shoot length was higher in PL at 8.06 Gy dose as compared to BL at 7.19 Gy whereas for EMS, $\mathrm{LD}_{50}$ was at par in both the landraces viz. $0.004 \%$ and $0.005 \%$ for BL and PL, respectively. Reduction in root length to an extent of $50 \%$ was caused by 2.569 Gy in BL and 2.479 in PL whereas for EMS, both the landraces had same $\mathrm{LD}_{50}(0.002 \%)$. At biologically comparable doses for different $\mathrm{M}_{1}$ parameters, PL was relatively more radio and chemo-sensitive than BL (Table 2), except for shoot length in both the landraces. However, in case of chemo-sensitivity, parallelism was found in both BL and PL for root length. Moreover, BL was more sensitive to both radio and chemo-sensitivity for germination \%, number of leaves and root length than PL. Mutability within landraces Chlorophyll mutant percentage varied from 0.09 to $0.29 \%$ in BL with EMS. Among the different chlorophyll mutants, chlorina mutants were found to be much higher in percentage followed by viridis and xantha mutants (Table 3). However, chlorophyll mutants ranged from $0.08 \%$ to $0.31 \%$ in PL with EMS. Xantha mutants were much higher in \% followed by viridis and chlorina. Among the two landraces, BL showed maximum number of chlo- 
rophyll mutants as compared to PL. Moreover, the rate of production of chlorophyll mutants was $7.07 \%$ higher in BL as compared to PL with EMS. Chlorophyll mutation rate increased with an increase in the dose of mutagens up to a certain level, beyond which it decreased (Table 3). Further, the number of chlorophyll mutants varied from 59 to 184 in BL with gamma rays. Among the chlorophyll mutants, chlorina mutants (227) were maximum followed by xantha (190) and viridis (69). Among the different doses, $\mathrm{LD}_{50}(250$ Gy) exhibited maximum number of chlorophyll mutants. However, in PL, maximum number of chlorophyll mutants was exhibited by 250 Gy followed by 275 Gy and 225 Gy along with 100 Gy and 150 Gy which showed least number of mutants (45). Higher dose than LD50 produced lesser number of chlorophyll mutants. It increased from lower dose 100 Gy to 250 Gy. Among the different chlorophyll mutants obtained by both gamma rays and EMS, maximum number of xantha mutants were generated followed by chlorina and viridis.
BL produced 29\% higher chlorophyll mutants as compared to PL. These chlorophyll mutants could be used as genetic markers and can be employed in the study of photosynthesis, biogenesis of chloroplast and plastids. Mean performance of induced mutants in $\mathrm{M}_{2}$ generation. An induced mutant at 250 Gy of BL showed higher seed weight, pod length, early maturity and seed yield in comparison to untreated material i.e. control along with complete resistance against Colletotrichum lindemuthianum (Table 4). Similarly, 250 Gy, an induced mutant line of PL in $\mathrm{M}_{2}$ generation also exhibited moderate resistance against anthracnose along with higher seed yield in comparison to untreated seeds of PL. This line may be utilised as genetic stock for use as donor parent for the introgression of anthracnose resistant trait. An induced mutant line $(0.50 \%)$ of PL also manifested moderate resistance against anthracnose in $M_{2}$ generation along with higher seed yield and yield attributing traits as compared to control.

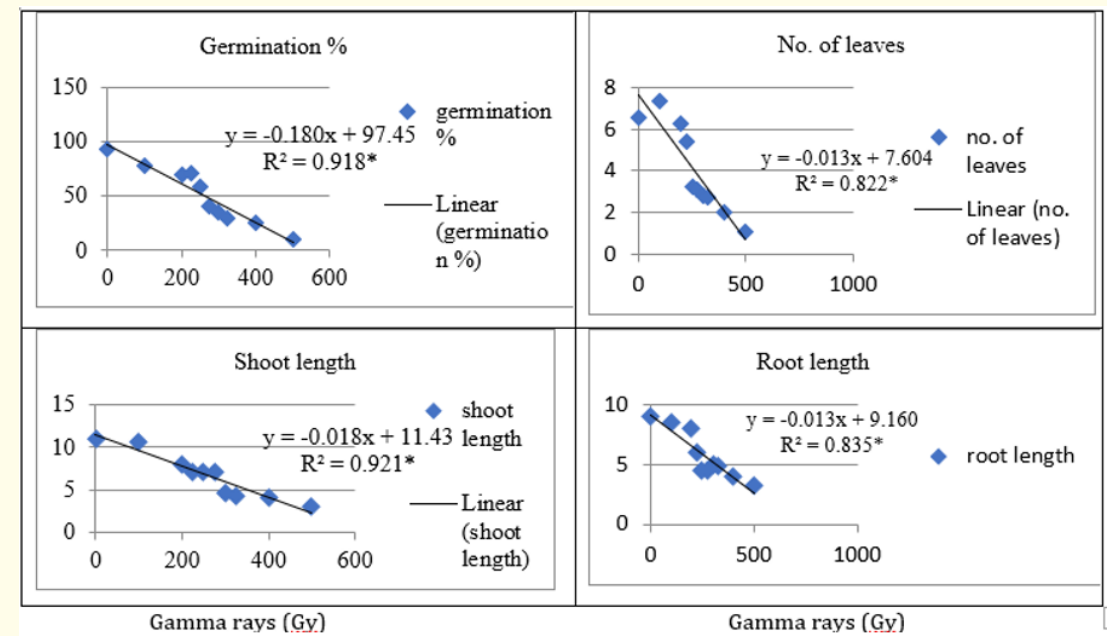

Figure 1a: Effects of gamma rays on different M1 biological parameters in Bhaderwah local (BL).

\begin{tabular}{|c|c|c|c|c|}
\hline Biological Parameters & Bhaderwah Local & Poonch Local & Bhaderwah Local & Poonch Local \\
\hline & \multicolumn{2}{|c|}{ Physical (Gamma rays (Gy) } & \multicolumn{2}{|c|}{ Chemical (EMS \%) } \\
\hline Germination \% & 248.058 & 234.167 & 0.626 & 0.573 \\
\hline No. of Leaves & 09.573 & 07.278 & 0.005 & 0.004 \\
\hline Shoot Length $(\mathrm{cm})$ & 07.198 & 08.060 & 0.004 & 0.005 \\
\hline Root Length(cm) & 02.569 & 02.479 & 0.002 & 0.002 \\
\hline
\end{tabular}

Table 1: $\mathrm{LD}_{50}$ values of landraces of Phaselous vulgaris $\mathrm{L}$. for different biological parameters in $\mathrm{M}_{1}$ generation. 
Induced Mutants in Locally Adapted Landraces of French Bean (Phaseolus vulgaris L.), their Mutagenic Sensitivity and Mutability for Crop Improvement

\begin{tabular}{|c|c|c|c|c|}
\hline Biological Parameters & Bhaderwah Local & $\begin{array}{l}\text { Poonch } \\
\text { Local }\end{array}$ & Bhaderwah Local & $\begin{array}{c}\text { Poonch } \\
\text { Local }\end{array}$ \\
\hline & \multicolumn{2}{|c|}{$\begin{array}{l}\text { Physical mutagen- Gamma rays } \\
\text { (Gy) }\end{array}$} & \multicolumn{2}{|c|}{ Chemical mutagen- (EMS \%) } \\
\hline Germination \% & \multicolumn{2}{|c|}{ BL $>$ PL } & \multicolumn{2}{|l|}{$\mathrm{BL}>\mathrm{PL}$} \\
\hline No. of Leaves & \multicolumn{2}{|l|}{$\mathrm{BL}>\mathrm{PL}$} & \multicolumn{2}{|c|}{$\mathrm{BL}>\mathrm{PL}$} \\
\hline Shoot Length $(\mathrm{cm})$ & \multicolumn{2}{|l|}{$\mathrm{PL}>\mathrm{BL}$} & \multicolumn{2}{|l|}{$\mathrm{PL}>\mathrm{BL}$} \\
\hline Root Length $(\mathrm{cm})$ & \multicolumn{2}{|l|}{$\mathrm{BL}>\mathrm{PL}$} & \multicolumn{2}{|l|}{$\mathrm{BL}=\mathrm{PL}$} \\
\hline
\end{tabular}

Table 2: Relative mutagen sensitivity of Rajmash landraces.

BL- Bhaderwah Local and PL- Poonch Local.

\begin{tabular}{|c|c|c|c|c|c|c|c|c|}
\hline Landraces & NPP & NPG & Albina & Chlorina & Xantha & Viridis & $\begin{array}{c}\text { Total no of } \\
\text { mutants }\end{array}$ & $\begin{array}{c}\text { Overall } \\
\text { frequency }(\%)\end{array}$ \\
\hline LR-1 (BL) & 500 & 489 & - & - & - & - & - & - \\
\hline $0.4 \%$ (SL) & 500 & 470 & - & $15(0.03 \%)$ & $12(0.03 \%)$ & $18(0.04 \%)$ & 45 & 0.09 \\
\hline $0.5 \% \mathrm{LD}_{50}$ & 500 & 450 & - & $54(0.12 \%)$ & $35(0.08 \%)$ & $40(0.08 \%)$ & 129 & 0.29 \\
\hline $0.6 \%(\mathrm{SH})$ & 500 & 424 & - & $36(0.08 \%)$ & $40(0.09 \%)$ & $40(0.09 \%)$ & 116 & 0.27 \\
\hline Total & - & - & - & 105 & 87 & 98 & 290 & 0.22 \\
\hline (PL) & 500 & 483 & - & - & - & - & - & - \\
\hline $0.4 \%(\mathrm{SL})$ & 425 & 420 & - & $10(0.02 \%)$ & $13(0.03 \%)$ & $14(0.03 \%)$ & 37 & 0.08 \\
\hline $0.5 \% \mathrm{LD}_{50}$ & 450 & 416 & - & $31(0.08 \%)$ & $58(0.14 \%)$ & $41(0.10 \%)$ & 130 & 0.31 \\
\hline $0.6 \%(\mathrm{SH})$ & 450 & 392 & - & $11(0.03 \%)$ & $40(0.10 \%)$ & $10(0.03 \%)$ & 61 & 0.16 \\
\hline Total & - & - & - & 52 & 111 & 65 & 228 & 0.18 \\
\hline Grand Total & - & - & - & 157 & 198 & 163 & 518 & \\
\hline LR-1 (BL) & 500 & 495 & - & - & - & - & - & - \\
\hline 100 Gy & 556 & 500 & 1 & 22 (0.04\%) & $25(0.05 \%)$ & $11(0.02 \%)$ & 59.0 & $0.12 \%$ \\
\hline 150Gy & 475 & 450 & - & $53(0.12 \%)$ & $40(0.08 \%)$ & $14(0.04 \%)$ & 107 & $0.24 \%$ \\
\hline 200Gy & 600 & 559 & - & $70(0.13 \%)$ & $55(0.10 \%)$ & $12(0.02 \%)$ & 137 & $0.25 \%$ \\
\hline 250Gy $\left(\mathrm{LD}_{50}\right)$ & 550 & 502 & 02 & $82(0.16) \%$ & $70(0.14 \%)$ & $32(0.06 \%$ & 184 & $0.37 \%$ \\
\hline Total & - & - & 03 & 227 & 190 & 69 & 487 & $0.75 \%$ \\
\hline LR-2 (PL) & 500 & 490 & - & - & - & - & - & - \\
\hline $100 \mathrm{~Gy}$ & 400 & 355 & - & $12(0.03 \%)$ & $15(0.04 \%)$ & $18(0.05 \%)$ & 45 & $0.13 \%$ \\
\hline 150Gy & 550 & 400 & - & $15(0.04 \%)$ & $10(0.03 \%)$ & $20(0.6 \%)$ & 45 & $0.13 \%$ \\
\hline 225Gy & 500 & 335 & - & $25(0.07 \%)$ & $22(0.07 \%)$ & $05(0.01 \%)$ & 52 & $0.16 \%$ \\
\hline 275 Gy & 456 & 300 & - & $10(0.03 \%)$ & $25(0.08)$ & $34(0.11 \%)$ & 69 & $0.23 \%$ \\
\hline 250 Gy $\left(L_{50}\right)$ & 600 & 522 & - & $56(0.10 \%)$ & $72(0.14 \%)$ & $38(0.07 \%)$ & 166 & $0.32 \%$ \\
\hline Total & - & - & & 118 & 144 & 115 & 377 & 0.19 \\
\hline
\end{tabular}

Table 3: Chlorophyll mutants' frequency in $\mathrm{M}_{2}$ population of Phaseolus vulgaris $\mathrm{L}$. 
Induced Mutants in Locally Adapted Landraces of French Bean (Phaseolus vulgaris L.), their Mutagenic Sensitivity and Mutability for Crop Improvement

\begin{tabular}{|c|c|c|c|c|c|c|c|}
\hline LR/Mutagens & Dose & $\begin{array}{c}100 \text { Seed wt } \\
\text { (g) }\end{array}$ & $\begin{array}{l}\text { Length of } \\
\text { Pod (cm) }\end{array}$ & $\begin{array}{c}\text { Days to } \\
\text { flowering }\end{array}$ & $\begin{array}{c}\text { Days to } \\
\text { maturity }\end{array}$ & $\begin{array}{c}\text { Yield/Plant } \\
\text { (g) }\end{array}$ & $\begin{array}{c}\text { Anthracnose } \\
\text { Reaction }\end{array}$ \\
\hline & BL-Control & 8.12 & 6.02 & 83 & 125 & 4.03 & $\mathrm{~S}$ \\
\hline \multirow{5}{*}{$\begin{array}{l}\text { Bhaderwah } \\
\text { Local } \\
\text { Gamma rays }\end{array}$} & 100 Gy BL & 15.05 & 7.24 & 72.80 & 114.33 & 4.72 & MR \\
\hline & 150 Gy BL & 15.24 & 7.08 & 76.00 & 115.19 & 6.61 & MS \\
\hline & 200 Gy BL & 11.78 & 7.13 & 74.00 & 113.08 & 7.87 & $\mathrm{R}$ \\
\hline & 250 Gy BL & 18.78 & 7.50 & 70.20 & 118.90 & 10.49 & $\mathrm{R}$ \\
\hline & PL-Control & 7.06 & 5.64 & 100 & 128 & 6.65 & $\mathrm{~S}$ \\
\hline \multirow[t]{5}{*}{ Poonch Local } & 100 Gy PL & 12.60 & 6.70 & 96.66 & 116.00 & 7.68 & $\mathrm{~S}$ \\
\hline & 150 Gy PL & 14.19 & 6.80 & 78.55 & 118.00 & 8.21 & MR \\
\hline & 200 Gy PL & 7.95 & 7.45 & 67.50 & 118.66 & 5.57 & HS \\
\hline & 225 Gy PL & 12.34 & 6.66 & 76.00 & 107.08 & 4.95 & MR \\
\hline & 250Gy PL & 15.41 & 7.32 & 68.33 & 114.16 & 8.90 & $\mathrm{MR}$ \\
\hline \multirow[t]{2}{*}{ EMS } & $0.50 \% \mathrm{PL}$ & 12.11 & 6.70 & 75.77 & 123.41 & 8.17 & $\mathrm{MR}$ \\
\hline & $0.60 \% \mathrm{PL}$ & 13.87 & 7.01 & 72.25 & 125.31 & 3.44 & HS \\
\hline
\end{tabular}

Table 4: Mean performance of $\mathrm{M}_{2}$ mutants for agro-morphological traits and reaction against anthracnose disease.

MR- Moderately Resistant, R- Resistant, S- Susceptible, MS- Moderately Susceptible and HS- Highly Susceptible, Gy- Gray.

\section{Discussion and Conclusion}

The different biological parameters showed a dose-dependent relationship in the $M_{1}$ population of two landraces exposed to both physical (gamma rays) and chemical (EMS) mutagens. Mostly, the biological parameter doses and traits in \% were inversely proportional to each other. The increasing doses of mutagens caused a progressive increase in the biological damage measured in terms of reduction in germination, number of leaves, root and shoot length (Figure 1a, 1b and 2a, 2b). Notably, [28] have reported negative correlation between all plant growth traits among common bean cultivars. The application of gamma rays affected plant survival rate considerably than the percentage of germination. Similar results have also been reported by $[13,14]$. The retardation in the root length was more pronounced than that found in the shoots (Table 1). The root system appeared to be relatively more sensitive to mutagens. This can possibly be due to an inhibition of division in root cells by mutagens, which exerts less effect on the elongation of shoot cells. The shoot growth is reported mainly due to the cell elongation while root growth is more dependent on cell division. [16] also found greater delay in rooting than that of shooting in Kalanchoe diagremmntiana leaves following irradiation with gamma rays. [1] found a positive relationship between seed size and mutagen sensitivity in Phaseolus species. Further, the reduction in $50 \%$ germination percentage occurred at 248.058 Gy gamma rays in BL and 234.167 Gy in PL whereas $0.626 \%$ and $0.573 \%$ reductions occurred in BL and PL, respectively with EMS. It is stated that reduction in the percentage of germination caused by high doses of radiations applied may result in reduction in the amount of internal growth regulators depending on the mutagens (Kiong., et al. 2008). Ellyfa., et al. (2007) also reported that the $\mathrm{LD}_{50}$ increased with increasing gamma radiation. At biologically comparable doses for different $M_{1}$ parameters, PL was relatively more radio and chemosensitive than BL (Table 2) except for shoot length, however, parallelism was observed in both the landraces under EMS. Generally, a parallelism occurs between the landraces for trait root length. Some of the radio sensitive mutants have also been found to possess increased sensitivity towards alkylating chemicals [4]. $\mathrm{LD}_{50}$ value for BL was determined as $248.058 \mathrm{~Gy}$ and 234.167 Gy for PL (Table 1). In case of EMS, the concentration of $0.20 \%$ was found to be the best. However, the $\mathrm{LD}_{50}$ value obtained in this study was found to be different from that indicated by them. This comparison also revealed that genotypes respond differently to the mutation dose and dosescaling studies must be performed for large-scale studies. The relationship in root length was more pronounced than that found in shoot length (Table 1). The root

Citation: Sanjeev Kumar., et al. "Induced Mutants in Locally Adapted Landraces of French Bean (Phaseolus vulgaris L.), their Mutagenic Sensitivity and Mutability for Crop Improvement". Acta Scientific Agriculture 5.12 (2021): 10-16. 
system appeared to be relatively more sensitive to mutagens. This can possibly be due to an inhibition of division in root cells by mutagens, which exert less effect on the elongation of shoot cells. [29] stated that 75Gy-175 Gy application is sufficient for lethality and mutation rates in two Cuban bean genotypes. [26] reported that $\mathrm{LD}_{50}$ value was found at $100 \mathrm{~Gy}$ for seed germination in Phaseolus lunatus. [10] also observed that the dose of 150 Gy was found to be most efficient among the different doses of gamma rays with few exceptions. The chlorophyll mutation frequency was $1.97 \%$ more induced by mutagen gamma rays than ethyl methane sulphonate (EMS). However, frequency of induced chlorophyll mutants was more in BL than PL in both the mutagens viz., gamma rays and EMS (Table 3). In general, gamma rays were more effective than EMS. Moreover, the frequency of induced chlorophyll mutants was $66.69 \%$ more by gamma rays than EMS. Similar results were also reported by $[12,13,28]$. Furthermore, chlorophyll mutation rate increased with an increase in the dose of mutagen up to $\mathrm{LD}_{50}$ in both the landraces for both the mutagens, beyond which it decreased (Table 3). The phenomenon has been attributed to intra somatic selection, reduction in the number of $\mathrm{M}_{2}$ plants produced by high sterile $M_{1}$ plants and other processes of gamete as well as zygote elimination. Similar results were also reported by [6,24]. [8] have also reported that frequency of chlorophyll mutations was dose dependent and increased with increasing dose of each mutagen. Thus, chlorophyll mutations could be exploited for identifying the threshold dose of a mutagen that would increase the probability of retrieving economically useful mutations in ensuing generations. An induced mutant of 250 Gy of BL showed higher seed weight, pod length, early maturity and seed yield in comparison to control along with complete resistance against $\mathrm{C}$. lindemuthianum (Table 4). It may have occurred due to beneficial mutation at dose $250 \mathrm{~Gy}$ of gamma rays $\left(\mathrm{LD}_{50}\right)$. This mutant line may be used as genetic stock for trait introgressions as well as for further screening towards development of an improved variety. An induced mutant line $(0.50 \%)$ of PL also manifested moderate resistance against anthracnose in $\mathrm{M}_{2}$ generation along with higher seed yield and yield attributing traits as compared to control. In conclusion, these mutant lines could be utilised as genetic stocks for french bean improvement programme in future crop research.

\section{Conflict of Interest}

The authors declare that there is no conflict of interest.

\section{Acknowledgement}

The authors are thankful to Board of Research in Nuclear Sciences (B.R.N.S.), Department of Atomic Energy (D.A.E.) Mumbai, Maharashtra India for financial assistance to conduct the study.

\section{Author Contributions}

SK, MS-conceived the study, conducted experiments and prepared original draft NM, AJS, SJ-formal analysis and helped in final editing JPS, MS-helped in field observations. All authors read and approved the final version of manuscript.

\section{Bibliography}

1. A1-Rubeai MAF. "Radio-sensitivity of dormant Phaseolus seeds". Journal Environmental and Experimental Botany 21 (1980): 71-74.

2. Badere RS and Choudhry AD. "Effectivity and efficiency of gamma rays, sodium azide and ethyl methane sulphonate in Linseed". Bioinfolet 4.3 (2007): 181-187.

3. Blixt S and Gottschalk W. "Mutation breeding in Leguminosae". 33 (1975): 33-85.

4. Brendel M., et al. "Common steps in the repair of alkylation and repair damage in yeast". Molecular Genetics and Genomics 106 (1970): 289-295.

5. Dhanavel D., et al. "Effectiveness and efficiency of chemical mutagens in Cowpea (Vigna unguiculata (L.) Walp.)". The African Journal of Biotechnology 7 (2008): 4116-4117.

6. Ellyfa K., et al. "Gamma Radio sensitivity Study on Snap Bean (Phaseolus vulgaris L.)". International Journal of Agricultural Research 2.9 (2007): 844-848.

7. Gaul H. "Mutations in plant breeding for forage and grain". Rad. on Bot 4.3 (1964): 151-232.

8. Goyal S., et al. "Frequency and spectrum of chlorophyll mutations induced by single and combination treatments of gamma rays and EMS in Urdbean". Asian Journal of Bio Science 12 (2019): 156-163.

9. Jain SM. "Mutagenesis in crop improvement under the climate change". Romanian Biotechnological Letters 15.2 (2010): 88106. 
10. Khar kwal MC. "A brief history of plant mutagenesis". In: Q. Y. Shu, B. P. Forster and H. Nakagawa (Editions.). Plant Mutation Breeding and Biotechnology (2012): 21.

11. Khar kwal MC. "Induced mutations in chickpea, frequency and spectrum of viable mutations". The Indian Journal of Genetics and Plant Breeding 59.4 (1999): 451-464.

12. Kiong A., et al. "Physiological responses of Orthosiphon stamineus plantlets to gamma irradiation". American-Eurasian Journal of Sustainable Agriculture 2 (2008): 135-139.

13. Kumar S., et al. "Induced chlorophyll mutations and mutagenic effectiveness and efficiency of ethyl methane sulphonate in horsegram (Macrotyloma uniflorum Roxb)". Green Farming 3.5 (2012): 151-54.

14. Kumar S. "Mutagenic effectiveness and efficiency in macrosperma lentil under mid hills of northwestern Himalayas". Journal of Crop Improvement 40.2 (2013): 182-185.

15. Lekharam J. "Induced genetic variability through physical and chemical mutagens in M3 and M4 populations of French bean (Phaseolus vulgaris L.)". The Indian Journal of Plant Genetic Resources 23.1 (2010): 44-50.

16. Mishra SD., et al. "Radiation induced delay in organogenesis of Kalanchoe daigremntiana leaves". Journal Environmental and Experimental Botany 20 (1980): 309-323.

17. Oladosu Y., et al. "Principle and application of plant mutagenesis in crop improvement: a review". Biotechnology and Biotechnological Equipments 30.1 (2016): 1-16.

18. Padmavathi T., et al. "Induced variability for different biological parameters in soybean". Journal of Cytology and Genetics 27 (1992): 175-177.

19. Pavadai P., et al. "Effect of gamma rays, EMS, DES and COH on protein and oil content in soybean". The Journal of Eco Biotechnology 2.4 (2010): 47-50.

20. Puchooa D. "In-vitro mutation breeding of Anthurium by gamma radiation". International Journal of Agriculture and Biology 7.1 (2005): 11-20.
21. Sagel Z., et al. "Nohutta Mutasyon Islahı”. In Ulusal nükleer bilimler ve teknolojileri kongresi (VIII Nat. Cong. of Nucl. Sci. and Techn.) (2009): 313-320.

22. Salve KM and More KD. "Effect of gamma radiation on seed germination, seedling height, seedling injury in Coriandrum sativum". International Journal of Life Science 2 (3): 223-25.

23. Sangsiri C., et al. "Gamma radiation induced mutations in mungbean". Science Asia (2005): 251-255.

24. Sharma SK and Sharma B. "Mutagen sensitivity and mutability in lentil". Theoretical and Applied Genetics 71 (1986): 820-825.

25. Sikder S., et al. "Induction of mutation in tomato by gamma irradiation and EMS". The Indian Journal of Genetics and Plant Breeding 73.4 (2013): 392-399.

26. Suresh D., et al. "Determination of lethal dose for gamma rays induced mutagenesis in butter bean (Phaseolus lunatus L.) variety KKL-1". International Journal of Current Microbiology and Applied Sciences 6.3 (2017): 712-717.

27. Thilagavathi $\mathrm{C}$ and Mullainathan L. "Isolation of macro mutants and mutagenic effectiveness, efficiency in black gram". Global International Journal of Molecular Sciences 4.2 (2009): 76-79.

28. Ulukapi K and Ozmen SF. "Study of the effect of irradiation (60Co) on M1 plants of common bean cultivars and determined of proper doses for mutation breeding". Journal of Radiation Research and Applied Sciences 11 (2018): 157-161.

29. Yankulov MT., et al. "Algunos aspectos sobre la sensibilidady mutablidad de dosvariedadesdefrijol por influencia de raoyos gamma Co60 y etil-metan-sulfonator (EMS)". Ciencias de la Agricultura 7 (1980): 59-64.

Volume 5 Issue 12 December 2021 (C) All rights are reserved by Sanjeev Kumar., et al. 